\title{
Making Trans-Gender Healthcare a Priority in India- Journey towards Social Inclusion Govind K. Bansal ${ }^{1}$, Shibu John ${ }^{2}$
}

${ }^{1}$ Research Scholar, Department of Healthcare \& Pharmaceutical Management, School of Management and Business Studies, Jamia Hamdard, Delhi; ${ }^{2}$ Professor and HoD, Department of Healthcare \& Pharmaceutical Management, School of Management and Business Studies, Jamia Hamdard, Delhi.

\begin{tabular}{|c|c|c|c|c|c|c|c|c|}
\hline Abstract & Introduction & Methodology & Results & Conclusion & $\underline{\text { References }}$ & Citation & \multicolumn{2}{|c|}{ Tables / Figures } \\
\hline \multicolumn{9}{|c|}{ Corresponding Author } \\
\hline \multicolumn{8}{|c|}{$\begin{array}{l}\text { Prof. (Dr.) Shibu John, PhD, Professor and HoD, Department of Healthcare \& Pharmaceutical Management, } \\
\text { School of Management and Business Studies, Jamia Hamdard, Delhi. } \\
\text { E Mail ID: shibu.john14@gmail.com }\end{array}$} & 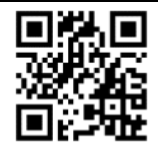 \\
\hline
\end{tabular}

\section{Citation}

Bansal GK, John S. Making Trans-Gender Healthcare a Priority in India- Journey towards Social Inclusion. Indian J Comm Health. 2020;32(2):324 - 329.

Source of Funding: Nil Conflict of Interest: None declared

\section{Article Cycle}

Received: 14/01/2020; Revision: 04/02/2020 Accepted: 22/02/2020; Published: 30/06/2020 This work is licensed under a Creative Commons Attribution 4.0 International License.

\section{Abstract}

Introduction: Transgender includes trans-men and trans-women, persons with intersex variations, gender-queers, and persons with socio-cultural identities. Any normal parent expects a binary outcome out of the nine months long pregnancy, however, for some, life changes when the expected outcome is different. Objective: The article tends to understand the life of transgender/Hijra in India with respect to specific healthcare needs along with constitutional mechanism to extend them their legal rights. Method: The researcher reviewed available literature to analyse the issues and challenges in accessing healthcare services by the transgender community. Grey literature and qualitative methods like consultation/ interviews with communities and subject experts were also done to supplement the study outcomes. Results: The study shows that after a long movement, transgender were formally given recognition in 21st century in India. Currently, we have a number to begin with. WHO's ICD-11 included "gender identity disorders" as "gender incongruence" in its new chapter on sexual health. Interactions with key experts and community reveals different specific needs of transgender population. Conclusion: Five points as way forward to improve health care accessibility of transgender in India: Creating an enabling environment before the next Census in India; addressing stigma and other issues that make transgender people vulnerable to health risks; extending equal human and legal rights to transgender; revising the medical curriculum so as to include a chapter on transgender health; and No Me Without Me.

\section{Keywords}

Transgender; Hijra; Social Inclusion; SRS; “No Me without Me”.

\section{Introduction}

The Transgender Protection Act was passed by the government recently. The Act refers, a transgender person as one, whose gender does not match the gender assigned at birth. It includes trans-men and trans-women, persons with intersex variations, gender-queers, and persons with socio-cultural identities, such as kinnar and hijra. Unfortunately, the society tends to classify an individual in binary form, either as male or female, which later on is used to choose the pronoun or to decide the kind of toys and clothes to welcome the new member. But, the real challenge for the family starts when the outcome is not binary.

Ask any layman about a transgender and one shall hear many versions and perceptions about them: it is an anomaly; kind of mental disturbance; cursing by the God, etc. The term "trans-gender" itself is the symbolic representation of crossing the boundaries, and it has been derived from the two different languages; the Latin word 'trans' and the English word 'gender'. The term "transgender" is generally used to describe those who transgress social gender norms. This is often used as an umbrella term to signify individuals who defy rigid, binary gender constructions and who expresses or presents a breaking or blurring of culturally prevalent stereotypical gender roles (1).

Globally, the terms third-gender and third-sex describe individuals who are biologically neither man nor woman. To different cultures or individuals, a third gender may represent an intermediate state between men and 
women- a state of being both, the state of being neither (neuter), the ability to cross or swap genders, another category altogether independent of men or women. The term hijra has been used especially in India, which has gained legal identity and is also used by many groups and individuals to describe themselves. Like the hijra, the third gender is, in many cultures, made up of biological males who takes on a feminine gender or sexual role. In certain cultures, they are usually seen as acceptable sexual partners for the masculine males.

\section{Transgender in India:}

Transgender have a strong historical background in India as evident from the ancient scriptures of Veda and Puranic literature like Ramayana and Mahabharata and comprise of Hijras, Kothis, Aravanis, Jogappas, Shiv-Shakthis etc. These are different kinds of transgender in India from times immemorial. Hijras have a recorded history in the Indian subcontinent from antiquity onwards as suggested by the Kama Sutra period.

As Manasi elaborates, by virtue of physical appearance and also psychologically, Hijras are neither men nor women, though they are like women with no female reproductive organ and no menstruation. Eunuch refers to an emasculated male and intersexed to a person whose genitals are ambiguously male-like at birth. Aravanis are biological males who self-identify themselves as a woman trapped in a male's body. Kothis can be described as biological males who show varying degrees of femininity which may be situational. Jogtas or Jogappas are those persons who have dedicated themselves to and serve as a servant of goddess (2).

The science and scientific community might have defined them; however, a common man still has many assumptions and questions about them like whether trans-men can have children or if Hijra has both types of reproductive organs? How do they use toilet- standing or squatting? What is under the drape (Saree or Salwar) that they wear? But perhaps, there would be very few who would actually be interested in knowing how they emerged from, perhaps, till the time, they have someone from the family or neighbourhood as Transgender.

Hijras are seen on auspicious occasions for want of their blessings as they are considered special in terms of bringing good fortune and luck. However, they are also one of the most traumatized and discriminated community as people want them out of fear, but do not want to relate to them or engage them for long.

\section{Aims \& Objectives}

The study was carried out in Delhi. Main objective of the study was to find ways of improving the provisioning of specific health care needs at Govt. tertiary care centre in Delhi.

\section{Material \& Methods}

The literature search was carried out mainly through search in electronic databases (PubMed, Google and
Google Scholar). Abstracts and findings are also included from unpublished $\mathrm{PhD}$ thesis of the primary author on the topic of health care accessibility issues among transgender community in Delhi region of India, for which data collection and analysis was still going on at the time of writing this article. Till the time of writing this article, in-depth interviews with more than 20 community members and more than 16 key informants were accomplished. The data collection started only after formal approval from the Student Research Advisory Committee of the institute. Consent was obtained from all the participants, who were more than 18 years of age.

\section{Results}

Understanding Gender:

Historically, terms sex and gender have been used interchangeably, but in modern times, they are being used distinctly and therefore, it is important to understand the differences between these two terms.

In normal usage, sex refers to the biological differences between males and females, such as the genitalia and genetic differences. Medical and scientific language further accentuates their differences in anatomical and physiological terms.

Men and Women, both have 46 Chromosomes. However, Women have 46 chromosomes with two $X$ chromosomes in the 23rd pair while Men have one $X$ and one $Y$ in the 23rd pair. Among the two, the $Y$ chromosome is dominant and is responsible for the development of testes in the embryo. With respect to hormones, both men and women have testosterone, oestrogen, and progesterone. However, men have higher levels of testosterone while women have higher levels of oestrogen and progesterone. Gender is a term that is often used to refer to ways in which people act, interact or feel about themselves, which are associated with men/boys and women/girls. In a nut shell, it can refer to the role of a male or female in society or an individual's concept of themselves. Aspects of biological sex are generally same across different cultures while aspects of gender, may not be.

Rather than being purely assigned by genetics, people often develop their gender roles in response to their environment and it includes family interactions, media, peers and education. Gender roles are highly fluid. Such examples can be seen in many societies, wherein men are increasingly taking on roles traditionally seen as belonging to women while women are playing the parts previously assigned mostly to men.

Over a period of time, Indians have also started using the western term Transgender alongside Hijra. Transgender issues are vast as they pertain to gender identity and rights issue. In India, much of the conversation on transgender relates to male to female gender transition and their association with feminism and/ or woman's identity, however, transgender is both male to female 
(transwoman) and female to male (transman) gender transgressions.

\section{Transgender (TG) population:}

There is a common misconception or negation that either few or no lesbian, gay, bisexual, and transgender (LGBT) people exist within our community. As a result, the health care needs of LGBT especially Transgender are often overlooked. A study published in The Lancet in June 2016 estimates 25 million people, or 0.3 to $0.5 \%$ of the global population, as transgender (3). Census, an exercise to count the population in India, never recognised Hijra/ Transgender until 2011. In 2011 Census, data of transgender was collected for the first time with details related to their employment, literacy and caste. According to which, number of persons who do not identify as 'male' or 'female' but as 'other' stands at $4,87,803(0.04 \%$ of the total population)(4). It also reported close to 55,000 children as transgender identified by their parents. The data have been primarily linked to the "Males" section as they are usually counted as men, but on request, they may be counted as women (5). At the same time, it does not segregate TG population among trans-men and transwomen. Due to this, it is impossible to comment on the actual transgender population, though the census has tried providing an estimate.

\section{Constitutional Protection for Transgender population in} India:

In legal parlance, atrocities against Hijra community started during the colonial period when the Criminal Tribes Act, 1871, was passed by the British colonial government mainly covering the northern India, in 1876, Bengal Presidency and with the Criminal Tribes Act, 1911, it covered Madras Presidency as well. Though it was primarily directed at tribal communities, various provisions also limited the rights of transgender and gender non-conforming communities and individuals in India. Hijras in particular were targeted under the Act.

The Criminal Tribes Act of 1871, created the category of "eunuch" to refer to the many, often unrelated gender non-conforming communities in India, including hijras. Under the Act, a eunuch could be either "respectable" or "suspicious." Respectable eunuchs did not engage in kidnapping, castration or sodomy, while suspicious eunuchs would perform in public and wear what British officials classified as female clothes. Thus, the Criminal Tribes Act actually banned all behaviour considered suspicious, including traditional hijra activities like public dancing or dressing in women's clothing (6).

Under the century-old Telangana Eunuchs Act 1329F, the state police had arbitrary powers to arrest and prosecute transgender persons. The Hyderabad High Court passed an interim order in September 2018, calling the draconian colonial legislation 'wholly unconstitutional' (7).

The Constitution of India came into existence in January 1950. Though acts like Criminal Tribes Act were denotified soon after Independence, Telangana Eunuchs Act
$1329 \mathrm{~F}$ continues to exist till now. The Article 14 of the Indian constitution, provides equality before law; Article 15- non-discrimination; Article 16- equality of opportunity in matters of public employment; Article 19- freedom of expression while Article 21- right to life. Karim mentions that the recognition of only the binary genders of male and female and the lack of legal measures to cater to the needs of the trans-community, contradicted a number of constitutional rights. Since the late 20th century, some hijra activists and Western Non- Government Organizations (NGOs) lobbied for official recognition of the hijra as a kind of "third sex" or "third gender", as neither man nor woman (8).

In 2014, in a landmark decision by the Supreme Court of India in National Legal Services Authority v. Union of India case, declared transgender people to be a 'third gender' and affirmed that the fundamental rights granted under the Constitution of India will be equally applicable to transgender people (9). The judgement also gave them the right to self-identification of their gender as male, female or third-gender. The apex court also directed the state and central governments to ensure that the transgender population has access to all schemes and entitlements to bring them at par with other citizens. However, transgender community had to wait for 64 years for this landmark judgement since we became Republic nation. Since the judgement came after 2011 census, it is speculated that the number of self-identified transgender will soar in Census 2021.

In September 2018, in a historic decision upholding privacy and non-discrimination of LGBT persons, the Supreme Court struck down the colonial-era sodomy law that criminalized consensual same-sex relations. The five judge bench unanimously ruled that consensual same-sex relationships are no longer a crime, deeming Section 377 "irrational, arbitrary and incomprehensible". The historic ruling followed a long struggle for the decriminalization of same-sex conduct in India (10).

The Transgender Persons (Protections of rights) Act, 2019

Based on the historic judgment of April 2014, the Rajya Sabha in April 2015, passed the Rights of Transgender Bill, 2014. This was a private member bill. However, the Government of India then passed another Bill-"Rights for Transgender Persons Bill, 2015", modifying on the 2014 bill by removing the provisions relating to Transgender Rights Court as well as the National and State Commissions. The 2015 Bill underwent further changes and Ministry of Social Justice and Empowerment (MoSJE), Govt. of India introduced another bill in the Lok Sabha in 2016 called "Transgender Persons (Protection of Rights) Bill 2016", which was passed in the Lok Sabha in December 2018. Since the bill could not pass through Rajya Sabha before the dissolution of Lok Sabha, it was lapsed.

The Transgender Persons (Protection of Rights) Bill, 2019, was passed by the Lok Sabha in August 2019 and by 
the Rajya Sabha, the upper house of the Parliament, on 26 November 2019. The president assented to it on 5 December 2019, upon which the act was notified in the Gazette of India. It was brought into effect from 10 January 2020 onwards vide a notification in the Gazette on the same day (11). The Act defines a transgender person as one whose gender does not match the gender assigned at birth. It includes trans-women and trans-men, persons with intersex variations, genderqueers and persons with socio-cultural identities, such as kinnar and hijra. Intersex variations is defined to mean a person, who at birth shows variation in his or her primary sexual characteristics, external genitalia, chromosomes or hormones from the normative standard of male or female body.

Though most of the 27 amendments mentioned to the original Bill were accepted, it eventually invited criticism from the transgender community and activists for various reasons (12). The Transgender Persons Act lays out a broad and inclusive definition of "transgender persons" and a clear distinction between identity-based recognition rights and the medical procedure(s) that some transgender people might want.

As explained by one of the transgender respondents Abheena Aher as part of the qualitative study by the author, the 2019 Bill states that a person would have the right to choose to be identified as a man, a woman or a transgender person, irrespective of the hormonal (replacement) therapy and Sex Reassignment Surgery (SRS). Despite this, the Act requires transgender person to go through a district magistrate and district screening committee to get certified as a trans-person. She further explained that a revised certificate may be obtained only if the individual undergoes surgery to confirm their gender. In case of denial of the certificate to the transgender, the Bill mentions no provisions for an appeal or review of the decision taken by the District Magistrate. Though the word Screening Committee was deleted from the original text of bill proposed in 2016, the process itself, as depicted in previous para, is no lesser than a screening committee.

\section{Health Care Accessibility issues for transgender:}

Amrita Gupta and Muthusamy Sivakami reported how poor utilisation of government health services and lack of awareness of government health insurance impose a heavy economic burden on transgender who are already vulnerable due to the stigma around their gender identity for a study conducted in slums of Mumbai (13).

Wider perception that being transgender is a mental disorder, no longer holds good. Air Cmdr Dr Sanjay Sharma (Retd), MD, Association for Transgender Health in India (ATHI), described the changes made in the World Health Organization's 11th revision of the International Classification of Diseases and Related Health Problems (ICD-11), from the earlier ICD-10 classification of mental and behavioural disorders in relation to sexuality and gender identity. A recent article in The Lancet mentions that gender identity disorders in ICD-10 have been reconceptualized as gender incongruence, and also moved to the new chapter on sexual health. The proposed classification of Paraphilic disorders distinguishes between conditions that are relevant to public health and clinical psychopathology and those that merely reflect private behaviour. ICD-10 categories related to sexual orientation have been recommended for deletion from ICD $11(14,15)$.

V.S. Balakrishnan in his article mentions how transgender women are marginalised and denied basic rights. He also mentions about specific needs of transgender in the form of hormone therapy and gender affirming treatment though everyone may not opt for it. The specific health issues includes depression, mood and anxiety disorders and suicidal ideation as part of mental health issues (16). HoD (Psychiatry) in a Govt. Medical College (expressed to be anonymous), New Delhi explained about different priorities under already over-burdened system. Gender Affirmation Surgeries (GAS) are conducted under the department of Plastic and Burns. Though the hospital is willing to take upon such surgeries, emergency cases outnumber the limited resources including specialist available in the department. In such scenario, expecting the quality services will be a far-fetched phenomenon. The HoD also expressed the specific need of dealing with mental health issues of transgender because of the stigma and discrimination they face in their daily life.

Dr RML Hospital, who hosted a conference with live streaming of GAS in 2016, does not have any GAS currently. Another psychiatrist, Dr Mina Chandra, Associate Professor (Psychiatry), explained how psychiatric assessment and clearance is the pre-requisite for conducting any GAS and why the process itself takes a lot of time as the seeker shall be undergoing an irreversible surgery and consequences.

"The protocols are followed as with any other surgery or organ donation procedures. None of the transgender visiting my department ever posted any complaint with respect to procedure adopted, behaviour of clinical or non-clinical staff in the facility. In fact, many changed their mind to undergo surgical procedure. It's not about saving ourselves from any kind of litigation as Govt provides enough support to fight such cases, but it is about helping my patients to take the right decision on their own and not under any influence."

She also attributed this to an extent to a better class visiting her department. In her view, being transgender is not only an individual issue but a societal issue leading to significantly higher mental health issues among them. She also expressed how class division among the transgender community gives rise to more such cases in lower strata of the society and how they are trapped in absence of ample opportunities to explore their potential and express their talent in mainstream society. 
This is also supplemented by the findings of H.G.

Virupaksha et al in their article suggesting that suicide rate and suicidal tendencies among transgender persons are considerably high compared to general population ranging from $32 \%$ to $50 \%$ across the countries. III treatment at health-care system is one of the major risk factors that influence the suicidal behaviour among transgender persons (17).

Limited literature is available with respect to transmen and their health care needs in India. The same was also felt while collecting data by primary author. Very few transmen could be contacted; those who could be contacted, many of them were reluctant about their transformation and sharing their journey. Those who could be brought to the discussion, also needed lot of persuasion, on the pre-condition of anonymity. Seeking physical examination in a govt. setting for any ailment including sexual needs, is a nightmare and challenge among transmen, who have undergone sexual transformation. This could be understood with the fact that a transman still carries a womb in his body which is prone to cervical/ uterine cancer in future years and same way a transwoman still carries a prostate gland with her. When it comes to the specific healthcare needs of transgender, Change of Sex or Gender Affirmation Surgery or Sex Reassignment Surgery, along with hormone replacement therapy, mental health issues including parental counselling are the issues which were highlighted during the preliminary findings of the qualitative research. Majority of the key subject experts and community members interviewed during the study, echoed the need of an orientation to health care providers including medical and para medical staff on handling the health needs of transgender community in the hospital- be it private or public.

\section{Discussion}

A holistic view of the interviews conducted and analysing in details for their sharing and life events, broadly synchronise with the summary of findings captured in series of articles published by Lancet in 2019 under 'Gender Equality, Norms and Health' $(18,19,20)$ and 'Transgender Health' $(21,22,23)$.

\section{Conclusion}

Indian society generally has good visible climate of acceptance and tolerance, however, few studies suggest limited public knowledge and understanding on same sex sexual orientation and people whose gender identity and expression are incongruent with their biological sex. Across the globe, there is paucity of data on issues related to Transgender including but not limited to accessibility to health care services, gender-based violence and other social and structural barriers.

The sex of a person is assigned at birth which would determine his or her rights in relation to marriage, adoption, inheritance, succession (property), taxation and welfare. Earlier laws in India recognised only the binary genders and did not have any provision for the rights of transgender people- who were known as "third gender" in local parlance. This absence of legislation for protecting transgender people in India, led to the discrimination of transgender in various areas of life.

Discrimination against Transgender has a full circle and starts right from their childhood. This was evident in the preliminary findings from the qualitative study done by the primary author himself. Rajesh el al also commented on the lack of orientation to faculty and staff members in higher education centres, discrimination prevalent on campus and lack of measures to deal with them in his article (24).

Based on the Supreme Court direction, it is an urgent need to realise the dream of passing the right of being equal to all transgender towards and inclusive, equitable and discrimination free society. Constitution of India has given them equal rights and therefore they cannot be ostracised from their natural rights.

This is beyond doubt that LGBT people face many health disparities and stigma in health care setting especially Govt. one, however, education and upbringing did make a lot of difference even in seeking health care from the Govt. facilities. It can be asserted that Govt. tertiary care centres are not well equipped to take care of burgeoning pressing needs, in terms of specialists or infrastructure.

Collecting sexual orientation and gender identity data of new and returning patients is critical for health care centres to provide a welcoming, inclusive and high-quality care to all patients.

\section{Recommendation}

Five ways forward which are proposed as part of the recommendations from this study:

1. Creating an enabling environment before counting the transgender population in next Census;

2. Addressing societal issues like stigma and discrimination that pushes transgender people towards health risks;

3. Provide them equal human and legal rights so that they can be covered by health and allied services;

4. Include a chapter on transgender health in the medical curriculum for new breed of doctors and orientation for existing medical officers including para medical staff; and

5. Involving transgender community while conducting health research on them- "No me without me"

\section{Limitation of the study}

Further research may be conducted in terms of quantifying the results from this qualitative study.

\section{Relevance of the study}

The study will help the policy makers while conducting census and revising the medical curriculum in future apart 
INDIAN JOURNAL OF COMMUNITY HEALTH / VOL 32 / ISSUE NO 02 / APR - JUN 2020 from a clear signal to involve transgender community while drafting policy decision for them.

\section{Authors Contribution}

GB: Overall conception and design, acquisition of data, analysis and its interpretation; drafted the article and responsible for final approval of the version to be published. SJ: Substantial contribution to the conception and design; revising the article critically for important intellectual content and equally responsible for final approval of the version to be published.

\section{Acknowledgement}

Technical Support Unit (TSU) Delhi under National AIDS Control Organisation (NACO), Association of Transgender Health in India (ATHI) and Transgender Community members in Delhi.

\section{References}

1. (2010). HIV/AIDS among men who have sex with men and transgender populations in South - East Asia. SEARO: WHO. Retrieved from https://apps.who.int/iris/handle/10665/205291

2. Bhushan, M. (2016). Analysis on Transgender Persons (Protection of Rights) Bill. Indian Law Journal. Retrieved September 28, 2019, from indialawjournal.org/analysis-on-transgender-persons.php

3. Reisner SL, Poteat T, Keatley J, Cabral M, Mothopeng T, Dunham E, Holland CE, Max R, Baral SD. Global health burden and needs of transgender populations: a review. Lancet. 2016 Jul 23;388(10042):412-436. doi: 10.1016/S0140-6736(16)00684-X. Epub 2016 Jun 17. Review. PubMed PMID: 27323919; PubMed Central PMCID: PMC7035595.[PubMed]

4. Gol. (n.d.). Primary Census Abstract Data for Others (India \& States/UTs), Census 2011. Ministry of Home Affairs, Office of the Registrar General \& Census Commissioner, India.

5. Nagarajan, R. (2014, May 30). First count of third gender in census: 4.9 lakh. Delhi: Times of India. Retrieved July 24, 2018, from https://timesofindia.indiatimes.com/india/First-count-of-thirdgender-in-census-4-9-lakh/articleshow/35741613.cms

6. Act No. XXVII of 1871: A Collection of Acts passed by the Governor General of India in Council in the Year 1871. (n.d.). Calcutta: Office of Superintendent of Government Printing, 1872

7. Staff, T. (2018, September 20). The News Minute. Retrieved from https://www.thenewsminute.com/article/law-targetingtransgender-persons-telangana-read-down-temporarily-88662

8. Karim, M. (2013, November 11). Hijras now a separate gender. (Dhaka Tribune) Retrieved July 5, 2018, from https://web.archive.org/web/20131111223441/http://www.dhak atribune.com/bangladesh/2013/nov/11/hijras-now-separategender

9. Mahapatra, D. (2014, April 15). Supreme Court recognizes transgenders as 'third gender. Retrieved September 15, 2019, from TImes of India: https://timesofindia.indiatimes.com/india/Supreme-Courtrecognizes-transgenders-as-thirdgender/articleshow/33767900.cms

10. India: Supreme Court Strikes Down Sodomy Law. (2018, September 6). Retrieved September 28, 2019, from Human Rights Watch: https://www.hrw.org/news/2018/09/06/india-supreme-courtstrikes-down-sodomy-law

11. Wikipedia. (2020, June 13). Transgender Persons (Protection of Rights) Act, 2019. Retrieved from Wikipedia: https://en.wikipedia.org/wiki/Transgender_Persons_(Protection_ of_Rights)_Act,_2019

12. Dharmadhikari, S. (2019, August 5). Trans Bill 2019 passed in Lok Sabha: Why the trans community in India is rejecting it. Retrieved
[Making Trans-Gender...] | Bansal GK et al September 28, 2019, from The News Minute: https://www.thenewsminute.com/article/trans-bill-2019-passedlok-sabha-why-trans-community-india-rejecting-it-106695

13. Amrita Gupta, M. S. Health and Healthcare Seeking Behaviour among Transgender in Mumbai: Beyond the Paradigm of HIV/AIDS. Social Science Spectrum, 2016;2(1),63-79. Retrieved September 2019,

from http://www.socialspectrum.in/index.php/sp/article/view/54/45

14. Reed, G. M. Disorders related to sexuality and gender identity in the ICD-11: revising the ICD-10 classification based on current scientific evidence, best clinical practices, and human rights considerations. World Psychiatry: official journal of the World Psychiatric Association (WPA), 2016;15(3), 205-221.

15. The Lancet. ICD-11. Lancet. 2019 Jun 8;393(10188):2275. doi: 10.1016/S0140-6736(19)31205-X. Epub 2019 Jun 6. PubMed PMID: 31180012.[PubMed]

16. Balakrishnan, V. (2016). Growing recognition of transgender health. World Health Organisation. doi:http://dx.doi.org/10.2471/BLT.16.021116

17. Virupaksha HG, Muralidhar D, Ramakrishna J. Suicide and Suicidal Behavior among Transgender Persons. Indian J Psychol Med. 2016 Nov-Dec;38(6):505-509. doi: 10.4103/0253-7176.194908. Review. PubMed PMID: 28031583; PubMed Central PMCID: PMC5178031.[PubMed]

18. Heise L, Greene ME, Opper N, Stavropoulou M, Harper C, Nascimento $M$, Zewdie D. Gender inequality and restrictive gender norms: framing the challenges to health. Lancet. 2019 Jun 15;393(10189):2440-2454. doi: 10.1016/S0140-6736(19)30652-X. Epub 2019 May 30. Review. PubMed PMID: 31155275.[PubMed]

19. Weber AM, Cislaghi B, Meausoone V, Abdalla S, Mejía-Guevara I, Loftus $P$, Hallgren E, Seff I, Stark L, Victora CG, Buffarini R, Barros AJD, Domingue BW, Bhushan D, Gupta R, Nagata JM, Shakya HB, Richter LM, Norris SA, Ngo TD, Chae S, Haberland N, McCarthy K, Cullen MR, Darmstadt GL. Gender norms and health: insights from global survey data. Lancet. 2019 Jun 15;393(10189):2455-2468. PubMed PMID: 31155273.[PubMed]

20. Hay K, McDougal L, Percival V, Henry S, Klugman J, Wurie H, Raven J, Shabalala F, Fielding-Miller R, Dey A, Dehingia N, Morgan R, Atmavilas $Y$, Saggurti N, Yore J, Blokhina E, Huque R, Barasa E, Bhan $\mathrm{N}$, Kharel C, Silverman JG, Raj A. Disrupting gender norms in health systems: making the case for change. Lancet. 2019 Jun 22;393(10190):2535-2549. doi: 10.1016/S0140-6736(19)30648-8. Epub 2019 May 30. Review. PubMed PMID: 31155270; PubMed Central PMCID: PMC7233290.[PubMed]

21. Winter S, Diamond M, Green J, Karasic D, Reed T, Whittle S, Wylie $\mathrm{K}$. Transgender people: health at the margins of society. Lancet. 2016 Jul 23;388(10042):390-400. doi: 10.1016/S01406736(16)00683-8. Epub 2016 Jun 17. Review. PubMed PMID: 27323925.[PubMed]

22. Wylie K, Knudson G, Khan SI, Bonierbale M, Watanyusakul S, Baral S. Serving transgender people: clinical care considerations and service delivery models in transgender health. Lancet. $2016 \mathrm{Jul}$ 23;388(10042):401-411. doi: 10.1016/S0140-6736(16)00682-6. Epub 2016 Jun 17. Review. PubMed PMID: 27323926.[PubMed]

23. Reisner SL, Poteat T, Keatley J, Cabral M, Mothopeng T, Dunham E, Holland CE, Max R, Baral SD. Global health burden and needs of transgender populations: a review. Lancet. 2016 Jul 23;388(10042):412-436. doi: 10.1016/S0140-6736(16)00684-X. Epub 2016 Jun 17. Review. PubMed PMID: 27323919; PubMed Central PMCID: PMC7035595.[PubMed]

24. Rajesh, A. N. A study on challenges and opportunities of mainstreaming transgender students in higher education institutions in India. Indian Journal of Adult Education, 2016;77(3), 39-52. 